\title{
Positive predictive value of ICD-10 codes for acute myocardial infarction in Japan: a validation study at a single center
}

Takashi Ando ${ }^{1}$, Nobuhiro Ooba², Mayumi Mochizuki ${ }^{1}$, Daisuke Koide ${ }^{3}$, Koichi Kimura ${ }^{4}$, Seitetz L. Lee ${ }^{5}$, Soko Setoguchi ${ }^{6}$ and Kiyoshi Kubota ${ }^{7^{*}}$ (i)

\begin{abstract}
Background: In Japan, several large healthcare databases have become available for research since the early 2000's. However, validation studies to examine the accuracy of these databases remain scarce. We conducted a validation study in order to estimate the positive predictive value (PPV) of local or ICD-10 codes for acute myocardial infarction (AMI) in Japanese claims. In particular, we examined whether the PPV differs between claims in the Diagnosis Procedure Combination case mix scheme (DPC claims) and in non-DPC claims.

Methods: We selected a random sample of 200 patients from all patients hospitalized at a large tertiary-care university hospital between January 1, 2009 and December 31, 2011 who had an inpatient claim assigned a local or ICD-10 code for AMI. We used a standardized data abstraction form to collect the relevant information from an electronic medical records system. Abstracted information was then categorized by a single cardiologist as being either definite or not having AMI.

Results: In a random sample of 200 patients, the average age was 67.7 years and the proportion of males was 78. $0 \%$. The PPV of the local or ICD-10 code for AMI was $82.5 \%$ in this sample of 200 patients. Further, of 178 patients who had an ICD-10 code for AMI based on any of the 7 types of condition codes in the DPC claims, the PPV was 89.3\%, whereas of the 161 patients who had an ICD-10 code for AMI based on any of 3 major types of condition codes in the DPC claims, the PPV was $93.8 \%$.

Conclusion: The PPV of the local or ICD-10 code for AMI was high for inpatient claims in Japan. The PPV was even higher for the ICD-10 code for AMI for those patients who received AMI care through the DPC case mix scheme. The current study was conducted in a single center, suggesting that a multi-center study involving different types of hospitals is needed in the future. The accuracy of condition codes for DPC claims in Japan may also be worth examining for conditions other than AMI such as stroke.
\end{abstract}

Keywords: Acute myocardial infarction, Validation study, Positive predictive value; database, Case mix, Diagnosis procedure combination

\footnotetext{
* Correspondence: kubotape-tky@umin.net

${ }^{7}$ NPO Drug Safety Research Unit Japan, Yushima 1-2-13-4F, Bunkyo-ku, Tokyo

114-0002, Japan

Full list of author information is available at the end of the article
}

(c) The Author(s). 2018 Open Access This article is distributed under the terms of the Creative Commons Attribution 4.0 International License (http://creativecommons.org/licenses/by/4.0/), which permits unrestricted use, distribution, and reproduction in any medium, provided you give appropriate credit to the original author(s) and the source, provide a link to the Creative Commons license, and indicate if changes were made. The Creative Commons Public Domain Dedication waiver (http://creativecommons.org/publicdomain/zero/1.0/) applies to the data made available in this article, unless otherwise stated. 


\section{Background}

Acute myocardial infarction (AMI) is one of the major causes of morbidity and mortality although its incidence varies between countries. For example, the incidence is much lower in Japan and other East Asian countries compared to the US and Europe [1]. Over the past two decades, the increased risk of AMI has been demonstrated to be associated with a variety of medications including non-steroidal anti-inflammatory drugs $[2,3]$, antidiabetic drugs $[4,5]$ and anti-human immunodeficiency virus drugs [6]. Administrative healthcare databases are increasingly used in observational studies enabling access to data for a large number of patients in a relatively short period of time and at a moderate cost [7]. Data indicating the occurrence of an outcome such as AMI should be accurate enough to make the study results reliable [8]. According to a systematic review on 30 validation studies of AMI published between 1984 and 2010 in North America and Europe, most studies assessed the International Classification of Disease and Related Health Problems 9th revision (ICD-9) code of AMI in hospitalized patients and found the positive predictive value (PPV) to be $93 \%$ or higher, and that the sensitivity and specificity were $86 \%$ or higher [9]. After 2010, along with further validation studies of AMI conducted in North America and Europe [10,11], studies in Asian countries also emerged. In a study in Korea, the PPV of the ICD-10 codes of AMI in insurance claims ranged from 71.4 to $73.1 \%$ [12]. In Taiwan, the PPV of the ICD-9 codes of AMI in insurance claims was $88 \%$ [13].

In Japan, the claims database [14] and the electronic healthcare database [15] became available on a commercial basis after 2000. A large nationwide database ("NDB Japan") was created in the late 2000's and the provision of data for research commenced in 2011 [16-18].

In Japan, under a universal health insurance system, reimbursements have been made on a fee-for-service basis since 1961 [19, 20]. In 2003, following the introduction of the concept of "case mix", the Diagnosis Procedures Combination (DPC) scheme was created for acute hospital care [20]. Differing from payment on a per case base in the Diagnosis Related Group (DRG) in the US, a DPC payment is made on a flat-rate per day basis as specified for each DPC classification [21]. About 5000 DPC classifications (in 2016) are defined by the combination of one disease group code and other elements [22]. The DPC is not a mandatory scheme that hospitals must follow. However by 2010, 1388 (18\%) of a total 7587 hospitals in the country adopted the DPC reimbursement scheme. As these DPC hospitals are relatively large, in 2010 it was observed that 455,148 (50.4\%) of a total 903,621 hospital beds for general and acute care in Japan were provided for by the DPC scheme [19]. The DPC scheme covers more than $90 \%$ of acute in-patient care for cancer, injuries and cardiovascular and other diseases [20].

As the linkage of claims data and other data sources, including hospital medical charts at the individual level, is currently strictly prohibited in Japan, any validation study is challenging. One of few possible validation studies available is to use the claims data of the individual hospitals.

We conducted a validation study to evaluate the validity of the condition codes of AMI using the past claims data in a hospital. In particular, we studied whether the validity varies between DPC and non-DPC (i.e., fee-for-service) claims.

\section{Methods}

A cross-sectional study was conducted at a large tertiary-care university hospital using all the fee-for-service claims and DPC claims issued in electronic format during the study period between January 1, 2009 and December 31, 2011. Those claims data issued in the past were available because any given hospital would normally keep claims data for at least 5 years according to government requirements. As basic data to characterize the study hospital, we examined the administrative data for the total number of hospitalized patients per year and the proportion of those hospitalized in the cardiology ward. In addition, we examined the top 3 diagnoses of all hospitalized patients as well as those patients in the cardiology ward.

The DPC hospitals issue a DPC claim for reimbursement. In addition, they may also issue a fee-for-service claim for care of diseases not covered by the DPC. On some occasions, the DPC hospitals may also issue a fee-for-service claim for acute in-patient care. For example, when a patient dies within $24 \mathrm{~h}$ after admission or when the length of stay in hospital exceeds the maximum limit specified for each DPC classification then the cost is not reimbursed in the DPC scheme but rather a fee-for-service claim is issued (with or without a DPC claim). In the current study, we assembled the information in the past DPC and non-DPC claims data in the hospital during the study period and constructed a data set, which is presumably the same as the data in the claims database.

The NDB and other claims databases contain files compiled by assembling DPC and fee-for-service claims information issued by hospitals as Comma Separated Values (CSV) files. Coding of medical conditions differs between the DPC and the fee-for-service claims (Table 1). In a fee-for-service claim, the condition is specified by a 7-digit local condition code. Many codes may be recorded in a single fee-for-service claim and there is virtually no limit to the number of condition codes for any one claim. In addition, the primary diagnosis code, although available, is sometimes given to no, or multiple, condition codes. In 
Table 1 Condition codes in claims for DPC and non-DPC hospitalizations

\begin{tabular}{|c|c|}
\hline Type of claims for hospitalization & Description \\
\hline \multicolumn{2}{|l|}{ I. Claims for DPC hospitalization } \\
\hline A. DPC code & $\begin{array}{l}\text { A mandatory code with } 14 \text { digits. The first } 6 \text { digits represent a group of conditions to which B-1 } \\
\text { below belongs, followed by the } 8 \text { digits indicating whether or not the patient had surgical } \\
\text { operation, other procedures and other relevant conditions }\end{array}$ \\
\hline B. ICD-10 $\operatorname{codes}^{\mathrm{a}}$ & ICD10 codes for 7 categories of conditions (B-1 to B-7 below) \\
\hline B-1. Greatest-resource condition & A mandatory code for a condition responsible for the greatest use of resources \\
\hline B-2. Trigger-for-hospitalization condition & A mandatory code for a condition that triggered hospitalization. \\
\hline B-3. Main condition & A mandatory code for a condition given as the main condition in the discharge summary \\
\hline B-4. Other condition & $\begin{array}{l}\text { A code for a condition required to record when the DPC code indicates that the patient had } \\
\text { a defined other relevant condition }\end{array}$ \\
\hline B-5. Second greatest-resource condition & An optional code for a condition responsible for the second greatest use of resources \\
\hline $\begin{array}{l}\text { B-6. Comorbidities at the time } \\
\text { of admission }\end{array}$ & A maximum of 4 codes for comorbidities that the patient had at the time of admission \\
\hline $\begin{array}{l}\text { B-7. Conditions occurring during } \\
\text { the hospitalization }\end{array}$ & A maximum of 4 codes for conditions occurring during the hospitalization \\
\hline \multicolumn{2}{|l|}{ II. Claims for non-DPC hospitalization } \\
\hline Condition codes & $\begin{array}{l}\text { Local condition codes with } 7 \text { digits. They are officially mapped to ICD-10 codes with a few } \\
\text { exceptions. No limitation is set to the maximum number of conditions per claim. }\end{array}$ \\
\hline Primary-condition flag & $\begin{array}{l}\text { The flag indicating that the condition is the primary condition. The flag is often not given to any } \\
\text { condition or given to two or more conditions }\end{array}$ \\
\hline
\end{tabular}

DPC Diagnosis Procedure Combination, ICD-10 International Classification of Diseases and Related Health Problems 10th Revision

aThe same condition code may be given to different types of conditions (e.g., the same ICD10 code may be given to all of B-1, B-2 and B-3)

the case of a DPC claim, two classes of condition codes are recorded [23]. One class (defined herein as the "class A" condition code) is a 6-digit disease group code. The disease group code is then used for the first 6 digits of a 14-digit DPC classification code. The other class (the "class B" condition code) consists of a maximum of 7 types of conditions that are recorded as a pair consisting of a 7-digit local condition code (as in the fee-for-service claim) and an ICD-10 code. Of the 7 types of class B condition codes, 3 are mandatory and always specified in every DPC claim (B-1 to B-3 in Table 1) [24]. One of these three (B-1 in Table 1) should belong to a disease group specified by the class A condition code.

In the claims in CSV-format, each single line pertains to one condition, one drug or one procedure, etc., and has a specific header. For example, the header "SY" is for a local condition code in the fee-for-service claim, "BU" for a $\mathrm{DPC}$ classification while "SB" is used for a pair of local and ICD-10 codes in the DPC claim. The NDB and other claims databases are constructed by assembling claims information by reference to a specific header. By similarly assembling the information of the past claims data at the study hospital, a data set, which is considered to be the same as the data in the claims database, was constructed and its accuracy was evaluated.

We identified 299 patients with DPC claims assigned an ICD-10 code of I21, I22 or I23 (AMI) as part of the 7 types of class B condition codes (in "SB" data) and/or fee-for-service claims with 7-digit local condition codes for AMI (in "SY" data) during the study period. When a patient was hospitalized twice or more due to AMI during the study period, we only used claims for the first hospitalization in this study. From the 299 patients with AMI claims, we selected a random sample of 200 patients. To select 200, we arranged 299 with AMI in ascending order according to a random variable assigned to each of them and simply selected the first 200 . In order to validate the condition code in the claims, information was abstracted from the electronic medical records system using a standardized data abstraction form employed in a validation study of AMI conducted in the Mini-Sentinel program in the US [10]. Referencing the abstracted information and, if required, the original data in the electronic medical records system, a cardiologist then categorized each case as either "definite AMI" vs "no AMI" while remaining blinded to the diagnosis code contained in the claims. As in a previous validation study of AMI [10], definite AMI was defined as the condition satisfying one of the 5 criteria: (i) detection of the rise and/or fall of cardiac biomarkers accompanied by ischemic symptoms, electrocardiographic (ECG) change or imaging evidence; (ii) sudden unexpected cardiac death; (iii) percutaneous coronary intervention (PCI) related MI (iv) coronary artery bypass grafting (CABG) related $\mathrm{MI}$ and $(\mathrm{v})$ postmortem pathologic finding. In the current study no case was classified as "probable MI" [10]. 


\section{Statistical analysis}

We estimated the PPV and its 95\% exact binomial confidence interval for a condition code of AMI: (i) in any claim; (ii) in any type of class B condition code (B1 to B7 in Table 1) in the DPC claim, and (iii) in one or more of the 3 major types (B1 to B3 in Table 1) in the DPC claim. We did not, however, estimate measures of validity other than the PPV such as the sensitivity, specificity and negative predictive values because: a) good registration data for MI covering the whole hospital was unavailable, and b) the limited resources precluded a chart review of all the patients in the hospital or a large enough random sample of the hospitalized patients during the study period. The study was approved by the ethics committee of University of Tokyo (Ref No. 3705). The statistical analysis was done with SAS V.9.4 (SAS Institute).

\section{Results}

During the study period (2009-2011), on average, a total of 25,519 patients were hospitalized per year of which $1660(6.5 \%)$ were in the cardiology ward in the study hospital. The first and second most frequent disease groups amongst all hospitalized patients were "liver cancer" and "angina/chronic ischemic cardiac disease" in each of the 3 years, while the third most frequent disease group was "lung cancer" in 2009 and "cataract" in 2010 and 2011. The first, second and third most frequent disease groups in the cardiology ward were "angina/chronic ischemic cardiac disease", "heart failure" and "tachyarrhythmia" in each of the 3 years. During the study period, AMI ranked 65th to 73rd of a total of 419 to 438 disease groups across the whole hospital and ranked 5th (following "bradyarrhythmia") of 66 to 74 disease groups in the cardiology ward.

The demographic and other characteristics of a random sample of 200 hospitalized patients with condition codes of AMI in any claims are shown in Table 2. The average age was 67.7 years and the proportion of males was $78.0 \%$. About one third of 200 patients were admitted in each year during the study period between 2009 and 2011. Of the sample of 200 hospitalized patients, the ICD-10 code for 104 patients (i.e., 52\%) was "Acute transmural myocardial infarction of anterior (I21.0) or inferior (I21.1) wall" whereas the ICD-10 code was "Acute myocardial infarction, unspecified (I21.9)" for 61 patients (i.e., 30.5\%). The code for "Subsequent myocardial infarction" (I22) was not used in any claim for the sample of 200 patients. As to therapeutic intervention for AMI, 140 (70\%) of 200 patients undertook PCI, thrombolytic therapy or CABG.

Table 3 shows the PPV for the condition codes for the different kinds of claims. The PPV was $82.5 \%$ in the 200 patients assigned an AMI condition code in any claim.

Table 2 A random sample of 200 hospitalized patients with an ICD10 diagnosis code of AMI

\begin{tabular}{|c|c|c|c|}
\hline & True AMl & No AMl & Total \\
\hline & $N=165$ & $N=35$ & $N=200$ \\
\hline Age $(S D)$ years & $67.3(12.6)$ & $69.4(9.0)$ & $67.7(12.0)$ \\
\hline Male, N (\%) & $126(76.4)$ & $30(85.7)$ & $156(78.0)$ \\
\hline \multicolumn{4}{|l|}{ Year of admission, $N(\%)$} \\
\hline 2009 & $61(37.0)$ & $12(34.3)$ & $73(36.5)$ \\
\hline 2010 & $51(30.9)$ & $11(31.4)$ & $62(31.0)$ \\
\hline 2011 & $53(32.1)$ & $12(34.3)$ & $65(32.5)$ \\
\hline \multicolumn{4}{|l|}{ ICD10 codes in claims, N (\%) } \\
\hline I21.0 Acute transmural myocardial infarction of anterior wall & $58(35.2)$ & $1(2.9)$ & $59(29.5)$ \\
\hline I21.1 Acute transmural myocardial infarction of inferior wall & $45(27.3)$ & $0(0)$ & $45(22.5)$ \\
\hline I21.2 Acute transmural myocardial infarction of other sites & $18(10.9)$ & $0(0)$ & $18(9.0)$ \\
\hline I21.3 Acute transmural myocardial infarction of unspecified site & $1(0.6)$ & $0(0)$ & $1(0.5)$ \\
\hline 121.4 Acute subendocardial myocardial infarction & $0(0)$ & $1(2.9)$ & $1(0.5)$ \\
\hline 121.9 Acute myocardial infarction, Unspecified & $43(26.1)$ & $18(51.4)$ & $61(30.5)$ \\
\hline Procedures for AMI in claims, N (\%) & $131(79.4)^{b}$ & $9(25.7)^{b}$ & $140(70.0)^{\mathrm{b}}$ \\
\hline Percutaneous coronary intervention (PCl) & $119(72.1)$ & $9(25.7)$ & $128(64.0)$ \\
\hline Thrombolytic therapy(TT) & $3(1.8)$ & $1(2.9)$ & $4(2.0)$ \\
\hline Coronary artery bypass graft(CABG) & $14(8.5)$ & $0(0)$ & $14(7.0)$ \\
\hline
\end{tabular}

ICD-10 International Classification of Diseases and Related Health Problems 10th Revision, AMI acute myocardial infarction, SD Standard Deviation

"No patient had the code for "Subsequent myocardial infarction" (I22)

${ }^{\mathrm{b}}$ The number (\%) of patients who had either PCI, TT or CABG 
Table 3 PPV of condition codes for AMl in DPC and non-DPC claims

\begin{tabular}{llll}
\hline Definition & N & True AMl & PPV (95\% confidence interval) \\
\hline Condition code for AMI in DPC or non-DPC claims & 200 & 165 & $82.5(76.5-87.5) \%$ \\
Condition code for AMI in DPC claims & 178 & 159 & $89.3(83.8-93.4) \%$ \\
Condition code for AMl in non-DPC claims only & 22 & 6 & $27.3(10.7-50.2) \%$ \\
Condition code for AMl in either of type B-1, B-2 or B-3 in DPC claims ${ }^{\text {b }}$ & 161 & 151 & $93.8(88.9-97.0) \%$ \\
Condition code for AMl in either of type B-5, B-6 or B-7 but not in B-1 B-2 or B-3 in DPC claims bc & 17 & 8 & $47.1(23.0-72.2) \%$
\end{tabular}

$P P V$ positive predictive value, $A M I$ acute myocardial infarction, DPC Diagnosis Procedure Combination

${ }^{a}$ Exact binomial confidence interval

${ }^{\mathrm{b}}$ See Table 1 for B-1, B-2, B-3, B-5, B-6 and B-7

"No patient had AMI as "other condition" (B-4)

The PPV was $89.3 \%$ for the 178 patients with a code of AMI in the DPC claims, and $93.8 \%$ for the 161 patients with a condition code of AMI as type B-1, B-2 or B-3 in the DPC claims.

\section{Discussion}

In the current study, the PPV of the condition code of AMI in the claims of hospitalized patients was high. The PPV was even higher when restricted to patients with an AMI code in the DPC claims, particularly when the condition was recorded as one of the 3 major types of class B condition codes (B-1, B-2 and B-3 in Table 1).

So far, only a few validation studies of the information contained in the databases of claims (and other healthcare data) have been conducted in Japan [25-29]. One reason for this scarcity may be that database study is still relatively new to clinical studies in Japan. In one of the recent studies in Japan [29], 23 of 315 patients randomly selected from 4 DPC hospitals were found to have AMI in chart review and the PPV, sensitivity, and specificity of an ICD-10 code of AMI were 92.3, 52.2 and 99.7\%, respectively.

We found that the PPV was higher in the DPC claims as compared to the fee-for-service claims. This observation may be relevant to the difference of the PPV of AMI in the studies conducted in Asian countries [12, 13]. For example, Taiwan introduced the DRG in 2010 for a wide variety of diseases including AMI [30] while the fee-for-service reimbursement is currently used for AMI in Korea where the use of the DRG-based reimbursement is limited to seven different diseases [31]. This difference of the reimbursement scheme might at least in part explain why the PPV in the study conducted in Korea [12] was lower than that in Taiwan [13].

In the current study, we found no patients who were hospitalized due to I22 (subsequent myocardial infarction) which is defined as "infarction of any myocardial site, occurring within 4 weeks ( 28 days) from onset of a previous infarction" [32]. The reason why none of the hospitalized patients had the diagnosis code of I 22 was not clear. However, one of the likely reasons is that the concept of "subsequent myocardial infarction" has not been widely accepted among Japanese physicians as they normally diagnose AMI irrespective of whether or not the infarction has occurred within 4 weeks from the onset of a previous infarction.

The main limitation of the current study is that the study is conducted at a single hospital. Thus, the PPV estimates in this study should be interpreted carefully as the results may not necessarily be generalized to other hospitals or to the claims databases. Another limitation was that the chart review was conducted by only one cardiologist so that inter-rater agreement could not be assessed.

The strength of this study is that we compared the PPV of the condition code for AMI between DPC and non-DPC (fee-for-service) claims and demonstrated that the PPV of the condition code in DPC claims was higher. This observation was expected because the condition code in a DPC claim is carefully selected by a physician at the hospital. We believe that the results in this study suggest that the use of condition codes in DPC claims may be further elaborated against patient's charts in validation studies of conditions other than AMI such as stroke for pharmacoepidemiology and other studies.

\section{Conclusion}

In this study conducted between January 1, 2009 and December 31, 2011, we found that the PPV of the condition code of AMI in the claims at a large tertiary hospital was high. When restricted to DPC claims, the PPV was even higher. As the study was conducted at a single hospital, more studies for AMI, including a multi-center study involving different types of hospitals, are needed in the future. The accuracy of condition codes in DPC claims in Japan may also be worth examining for conditions other than AMI such as stroke in the future. 


\section{Abbreviations}

AMI: acute myocardial infarction; DPC: Diagnosis procedure combination; DRG: Diagnosis Related Group; ICD: International Classification of Disease and Related Health Problems; PPV: Positive predictive value

\section{Acknowledgements}

We thank Ms. Kayoko Koide for providing the information regarding the top 3 group diagnoses and the number of hospitalized patients during the study period at the study hospital.

\section{Funding}

No funding was available for the current study.

\section{Availability of data and materials}

The datasets used and/or analysed during the current study are available from the corresponding author on reasonable request.

\section{Consent for publication}

The current study did not include details, images, or videos relating to an individual person and the consent for publication was not obtained as approved by the ethics committee.

\section{Authors' contributions}

$\mathrm{NO}, \mathrm{MM}$, SS and KK2 have made contributions to the conception and design of the study. TA, NO, and DK acquired data, KK1 classified cases into "definite" vs. "no AMI" and all authors including SLL interpreted the results, reviewed the manuscript and approved the manuscript in its current form.

\section{Ethics approval and consent to participate}

The study was approved by the ethics committee of the University of Tokyo (Ref No. 3705). The study used data already recorded and the ethics committee approved a waiver of informed consent.

\section{Competing interests}

The authors declare that none of the authors have any competing interests.

\section{Publisher's Note}

Springer Nature remains neutral with regard to jurisdictional claims in published maps and institutional affiliations.

\section{Author details}

'Division of Evaluation and Analysis of Drug Information, Keio University Faculty of Pharmacy, Tokyo, Japan. ${ }^{2}$ Department of Clinical Pharmacy, Nihon University School of Pharmacy, Chiba, Japan. ${ }^{3}$ Department of Biostatistics \& Bioinformatics Graduate School of Medicine The University of Tokyo, Tokyo, Japan. ${ }^{4}$ Departments of Advanced Medical Science, The Institute of Medical Science, The University of Tokyo, Tokyo, Japan. ${ }^{5}$ Department of Cardiovascular Medicine, University of Tokyo, Tokyo, Japan. ${ }^{6}$ Duke Clinical Research Institute, Durham, NC, USA. ${ }^{7} \mathrm{NPO}$ Drug Safety Research Unit Japan, Yushima 1-2-13-4F, Bunkyo-ku, Tokyo 114-0002, Japan.

\section{Received: 3 May 2018 Accepted: 16 November 2018}

\section{Published online: 26 November 2018}

\section{References}

1. Cui Y, Hao K, Takahash J, Miyata S, Shindo T, Nishimiya K, et al. Age-specific trends in the incidence and in-hospital mortality of acute myocardial infarction over 30 years in Japan: report from the Miyagi AMl registry study. Circ J. 2017:81:520-8.

2. Bresalier RS, Sandler RS, Quan H, Bolognese JA, Oxenius B, Horgan K, et al. Cardiovascular events associated with rofecoxib in a colorectal adenoma chemoprevention trial. N Engl J Med. 2005;352:1092-102.

3. Bally M, Dendukuri N, Rich B, Nadeau L, Helin-Salmivaara G, et al. Risk of acute myocardial infarction with NSAIDs in real world use: bayesian metaanalysis of individual patient data. BMJ. 2017; 1909:357.

4. Nissen SE, Wolski K. Effect of rosiglitazone on the risk of myocardial infarction and death from cardiovascular causes. N Engl J Med. 2007;356: 2457-71.

5. Loke YK, Kwok CS, Singh S. Comparative cardiovascular effects of thiazolidinediones: systematic review and meta-analysis of observational studies. BMJ. 2011;342:d1309.
6. Bavinger C, Bendavid E, Niehaus K, Olshen RA, Olkin I, Sundaram V, et al. Risk of cardiovascular disease from antiretroviral therapy for HIV: a systematic review. PLoS One. 2013;8:e59551.

7. Strom BL. Overview of automated databases in pharmacoepidemiology. In: Strom BL, Kimmel SE, Hennessy S, editors. Pharmacoepidemiology. 5th ed. Chichester: John Wiley \& Sons; 2012. p. 158-62.

8. West SL, Ritchey ME, Poole C. Validity of pharmacoepidemiologic drug and diagnosis data. In: Strom BL, Kimmel SE, Hennessy S, editors.

Pharmacoepidemiology. 5th ed. Chichester: John Wiley \& Sons; 2012. p. 775-94.

9. McCormick N, Lacaille D, Bhole V, Avina-Zubieta JA. Validity of myocardial infarction diagnoses in administrative databases: a systematic review. PLoS One. 2014;9:e92286.

10. Cutrona SL, Toh S, lyer A, Foy S, Daniel GW, Nair VP, et al. Validation of acute myocardial infarction in the Food and Drug Administration's minisentinel program. Pharmacoepidemiol Drug Saf. 2013;22:40-54.

11. Sundbøll J, Adelborg K, Munch T, Frøslev T, Sørensen HT, Bøtker HE, et al. Positive predictive value of cardiovascular diagnoses in the Danish National Patient Registry: a validation study. BMJ Open. 2016;6:e012832.

12. Kimm H, Yun JE, Lee $S H$, Jang Y, Jee SH. Validity of the diagnosis of acute myocardial infarction in Korean national medical health insurance claims data: the Korean heart study. Korean Circ J. 2012;42:10-5.

13. Cheng CC, Lee CH, Chen PS, Li YH, Lin SJ, Yang YHK. Validation of acute myocardial infarction cases in the national health insurance research database in Taiwan. J Epidemiol. 2014;24:500-7.

14. Kimura S, Sato T, Ikeda S, Noda M, Nakayama T. Development of a database of health insurance claims: standardization of disease classifications and anonymous record linkage. J Epidemiol. 2010;20:413-9.

15. Urushihara H, Taketsuna M, Liu Y, Oda E, Nakamura M, Nishiuma S, et al. Increased risk of acute pancreatitis in patients with type 2 diabetes: an observational study using a Japanese hospital database. PLoS One. 2012;7: e53224.

16. Kubota K, Kamijima Y, Sato T, Ooba N, Koide D, lizuka H, et al. Epidemiology of psoriasis and palmoplantar pustulosis: a nationwide study using the Japanese national claims database. BMJ Open. 2015;5:e066450.

17. Okumura Y, Sakata N, Takahashi K, Nishi D, Tachimori H. Epidemiology of overdose episodes from the period prior to hospitalization for drug poisoning until discharge in Japan: an exploratory descriptive study using a nationwide claims database. J Epidemiol. 2017; https://doi.org/10.1016/j.je.2016.08.010.

18. Matsuda S, Fujimori K. The claim database in Japan. Asian Pacific Journal of Disease Management. 2012;6:55-9.

19. Ishii M. DRG/PPS and DPC/PDPS as prospective payment systems. Japan Med Assoc J. 2012:55:279-91.

20. Matsuda S, Ishikawa KB, Kuwabara K, Fujimori K, Fushimi K, Hashimoto H. Development and use of the Japanese case-mix system. Eur Secur. 2008;14: 25-30.

21. Anderson G, Ikegami N. How can Japan's DPC inpatient hospital payment system be strengthened? Report of the CSIS global health policy center. 2011. https://csis-prod.s3.amazonaws.com/s3fs-public/legacy_files/files/publication/ 111028_Anderson_HospitalPayment_WEB.pdf. Accessed 14 Aug 2017.

22. Ministry of Health, Welfare and Labour. The expense list for Diagnosis Procedure Combination. http://www.mhlw.go.jp/stf/seisakunitsuite/bunya/ 0000039920.html (in Japanese). Accessed 14 Aug 2017.

23. Health Insurance Claims Review \& Reimbursement Services. Guidance for electronic claims for the system of electronic processing of claims - DPC http://www.ssk.or.jp/seikyushiharai/rezept/iryokikan/iryokikan_02.files/jiki_. d01.pdf (in Japanese). Accessed 14 Aug 2017.

24. Ministry of Health, Welfare and Labour. On items included in healthcare claims. http://www.mhlw.go.jp/file/06-Seisakujouhou-12400000-Hokenkyoku/ 0000041953.pdf (in Japanese). Accessed 14 Aug 2017.

25. Ooba N, Setoguchi S, Ando T, Sato T, Yamaguchi T, Mochizuki M, Kubota K. Claims-based definition of death in Japanese claims database: validity and implications. PloS ONE. 2013;8:e66116.

26. Sato I, Yagata H, Ohashi Y. The accuracy of Japanese claims data in identifying breast cancer cases. Biol Pharm Bull. 2015;38:53-7.

27. Tanaka S, Hagino H, Isizuka A, Miyazaki T, Yamamoto T, Hosoi T. Validation study of claims-based definitions of suspected atypical femoral fractures using clinical information. Jpn J Pharmacoepidemiol. 2016;21:13-9.

28. Yamaguchi T, Fui T, Akagi M, Abe Y, Nakamura M, Yamada N, et al. The epidemiological study of venous thromboembolism and bleeding events using a Japanese healthcare database: validation study. Jpn J Drug Infor. 2015;17:87-93. 
29. Yamana H, Moriwaki M, Horiguchi H, Kodan M, Fushimi K, Yasunaga H. Validity of diagnoses, procedures, and laboratory data in Japanese administrative data. J Epidemiol. 2017; https://doi.org/10.1016/j.je.2016.09.009.

30. Kuo CY, Yu LC, Chen HC, Chan CL. Comparison of Models for the Prediction of Medical Costs of Spinal Fusion in Taiwan Diagnosis-Related Groups by Machine Learning Algorithms. Healthc Inform Res. 2018;24:29-37.

31. Yoo RN, Chung CW, Kim JW. Evaluating the efficacy of the current diagnosisrelated group reimbursement system for laparoscopic appendectomy at a single institute in Korea. Ann Surg Treat Res. 2014;87:148-55.

32. World Health Organization. ICD-10 online versions. http://www.who.int/ classifications/icd/icdonlineversions/en/ Accessed 14 Aug 2017.

Ready to submit your research? Choose BMC and benefit from:

- fast, convenient online submission

- thorough peer review by experienced researchers in your field

- rapid publication on acceptance

- support for research data, including large and complex data types

- gold Open Access which fosters wider collaboration and increased citations

- maximum visibility for your research: over $100 \mathrm{M}$ website views per year

At $\mathrm{BMC}$, research is always in progress.

Learn more biomedcentral.com/submissions 